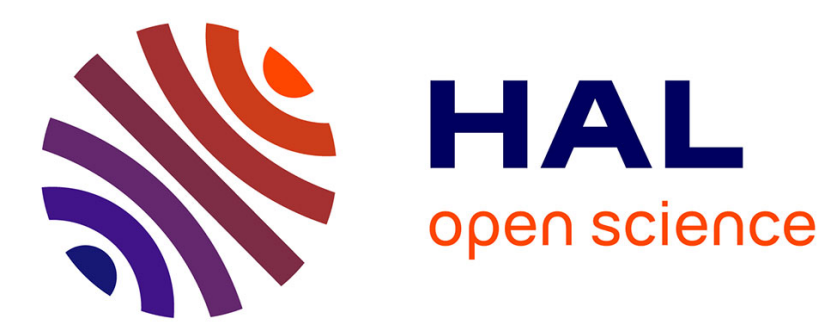

\title{
Chatter milling modeling of active magnetic bearing spindle in high-speed domain
}

\author{
Etienne Gourc, Sébastien Seguy, Lionel Arnaud
}

\section{To cite this version:}

Etienne Gourc, Sébastien Seguy, Lionel Arnaud. Chatter milling modeling of active magnetic bearing spindle in high-speed domain. International Journal of Machine Tools and Manufacture, 2011, 51 (12), pp.928-936. 10.1016/j.ijmachtools.2011.08.008 . hal-00752041

\section{HAL Id: hal-00752041 \\ https://hal.science/hal-00752041}

Submitted on 14 Nov 2012

HAL is a multi-disciplinary open access archive for the deposit and dissemination of scientific research documents, whether they are published or not. The documents may come from teaching and research institutions in France or abroad, or from public or private research centers.
L'archive ouverte pluridisciplinaire HAL, est destinée au dépôt et à la diffusion de documents scientifiques de niveau recherche, publiés ou non, émanant des établissements d'enseignement et de recherche français ou étrangers, des laboratoires publics ou privés. 


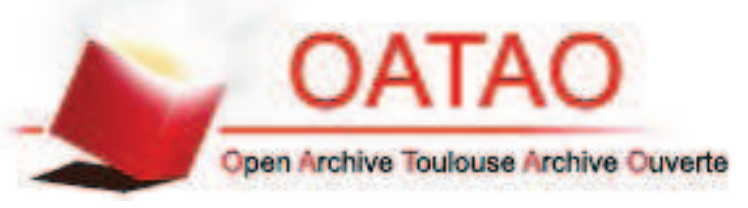

\section{Open Archive TOULOUSE Archive Ouverte (OATAO)}

OATAO is an open access repository that collects the work of Toulouse researchers and makes it freely available over the web where possible.

This is an author-deposited version published in : http://oatao.univ-toulouse.fr/ Eprints ID : 6381

To link to this article : DOI: 10. 1016/ j.ijmachtools.2011.08.008

URL : http://dx.doi.org/10.1016/j.ijmachtools.2011.08.008

To cite this version : Gourc, Etienne and Seguy, Sebastien and Arnaud, Lionel Chatter milling modeling of active magnetic bearing spindle in high-speed domain. (2011) International Journal of Machine Tools and Manufacture, vol. 51 ( $\left.\mathrm{n}^{\circ} 12\right)$. pp. 928-936. ISSN 0890-6955

Any correspondence concerning this service should be sent to the repository administrator: staff-oatao@listes.diff.inp-toulouse.fr 


\title{
Chatter milling modeling of active magnetic bearing spindle in high-speed domain
}

\author{
Etienne Gourc ${ }^{\mathrm{a}}$, Sébastien Seguy ${ }^{\mathrm{a}, *}$, Lionel Arnaud ${ }^{\mathrm{b}}$ \\ a Université de Toulouse, INSA, ICA (Institut Clément Ader), 135 avenue de Rangueil, F-31077 Toulouse cedex 4, France \\ ${ }^{\mathrm{b}}$ Université de Toulouse, ENIT (École Nationale d'Ingénieurs de Tarbes), LGP (Laboratoire Génie de Production), 47 avenue d'Azereix, BP 1629, F-65016 Tarbes cedex, France
}

\begin{abstract}
A B S T R A C T
A new dynamical modeling of Active Magnetic Bearing Spindle (AMBS) to identify machining stability of High Speed Milling (HSM) is presented. This original modeling includes all the minimum required parameters for stability analysis of AMBS machining. The stability diagram generated with this new model is compared to classical stability lobes theory. Thus, behavior's specificities are highlighted, especially the major importance of forced vibrations for AMBS. Then a sensitivity study shows impacts of several parameters of the controller. For example, gain adjustment shows improvements on stability. Side milling ramp test is used to quickly evaluate the stability. Finally, the simulation results are then validated by HSM cutting tests on a 5 axis machining center with AMBS.
\end{abstract}

\section{Introduction}

Currently, parts produced by machining still represent an important proportion of mechanical industrial production. Unfortunately, the productivity of machining operations at high speed is still severely limited by machining vibrations, so called chatter. It degrades the surface roughness of the part, increases the tool wear and reduces the spindle life span.

The early work of Tobias [1] in the 50s, have presented the phenomenon of regenerative effect as the main cause of chatter. The modeling of this phenomenon induces Delay Differential Equation (DDE). A first approach is to study the asymptotic stability of this equation. The stability diagram - well known as stability lobes - obtained make it possible to choose the maximum axial depth of cut for a given spindle speed associated with a chatter free machining. This approach initially dedicated to turning process [2] has been widely extended and democratized by the work of Altintas and Budak for milling process [3-5]. This method is interesting because, it leads to an analytic expression of the stability lobes. Recently, improved methods have been developed with a more detailed stability analysis, see for example [6-9]. Thus, for high-speed milling with low radial depth of cut and low

\footnotetext{
*Corresponding author. Tel.: +33 561559 222; fax: +33 561559950.

E-mail addresses: etienne.gourc@insa-toulouse.fr (E. Gourc) sebastien.seguy@insa-toulouse.fr (S. Seguy), lionel.arnaud@enit.fr (L. Arnaud).
}

helix angle, a new kind of unstable zones has been detected, called period-doubling or flip bifurcation [10].

In addition to these frequency approaches, Time Domain Simulation (TDS) was also developed with increasing computing capacity. In this case, the equation of motion is integrated step by step, in order to obtain more detailed information about the process such as the amplitude of the vibrations, the chip thickness, or the cutting forces during the tool's rotation [11-13]. The improvements of these approaches allows even simulation of the milled surface roughness $[14,15]$. These approaches are very powerful and can take into account all aspects of machining, even the non-linear effect of ploughing [14] or the non-linearity when the tool leave the cut during strong vibrations [11].

However, in many realistic cases, such for thin walled part machining, it is very difficult or impossible to select stable cutting conditions (spindle speed and depth of cut) for all the machining operation [16]. Classical solutions are based on machining strategies that maximize the dynamical stiffness of the mechanical components during the machining [17]. Others solutions are based on the damping effect obtained by reducing the cutting speed or, better by adding specific damper devices [18]. Tools with variable pitches [19] or with variable helix angles [20] can also be used to suppress chatter. A similar technique is to disturb the regenerative effect by spindle speed variation [21-23]. The idea of these last techniques is that the tooth pass frequency is varying; in this way, the regenerative effect is disturbed and this may significantly reduce the self-excited vibrations for specific spindle speeds. However, despite numerous academic 
studies on this topic, only the variable helix angle is widely used in industry.

During the 2000s, the development of Active Magnetic Bearing Spindles (AMBS) became very fast with several manufacturers in competition. A quite large bibliography is also available, see for example [24-27]. A major advantage of AMBS was supposed to be their life span, much larger than the conventional roller bearing spindle [27] and also their robustness to accidental force impact. This contactless technology, can also achieve very high speeds, but not yet very high power. In recent work on a micro milling machine with specific controllers, the spindle speed reached is over $150000 \mathrm{rpm}$ [28]. In addition to these advantages, it is also very easy to use all the included sensors and feedback currents, for position and force measurement. For example, Auchet et al. [29] developed a method for indirect cutting force measurement by analyzing the command voltage of AMBS. Chen and Knospe developed approaches to maximize damping, using a supplementary active magnetic bearing on the spindle, and some approaches to actively control chatter on dedicated simplified test bench [27,30,31]. Kyung and Lee [32] have studied the stability of AMBS machining, but only for conventional spindle speeds. To the best knowledge of the authors, all the work made on stability analysis of AMBS was made only for low spindle speeds, corresponding to conventional cutting speed.

In this paper, the modeling of AMBS is developed and analyzed in the high-speed domain, up to $40000 \mathrm{rpm}$, corresponding to the first Hopf and flip lobes. A new original AMBS machining modeling is proposed, and the results are confirmed by experiments. The structure of the paper is as follows. First, the model is presented in Section 2, then, the stability properties are predicted in Section 3. Experimental verifications are provided in Section 4. Finally, the paper is concluded in Section 5.

\section{Modeling of Active Magnetic Bearing Spindle machining}

\subsection{Mechanical modeling of the spindle}

The analysis of the machining stability at high spindle speed requires taking into account the spindle modal behavior. Analytical models of the spindle and measurements have shown that gyroscopic effect on modal frequencies is less that $1 \mathrm{~Hz}$, for the resonant frequency around $1 \mathrm{kHz}$ up to $40000 \mathrm{rpm}$. Thus, gyroscopic effect will not be taken into account in this study. Also, the unbalance is not taken into account because a part of the control algorithm, not defined here, is designed to center the rotation axis of the spindle at his inertia axis and thus avoid unbalance force compensation.

The $x$ displacement of a point $M$ of the center of the rotor located at height $z$ is defined by $u(z, t)$ (see Fig. 1).

The point $M(0)$ corresponds to the end of the tool, the points $M(A)$ and $M(B)$ are at the level of the A and B magnetic bearings. The modal base is used to represent the vibrations of the spindle

$u(z, t)=\sum_{i=1}^{n} \varphi_{i}(z) q_{i}(t)$

$\varphi_{i}(z)$ is the $i$ th modal shape, associated to the natural pulsation $\omega_{i}$ and the modal displacement coefficient $q_{i}(t)$, with

$\omega_{i}=\sqrt{\frac{k_{i}}{m_{i}}}$

Modal displacement $q_{i}(t)$ is obtained by solving the Newton equation

$\left\{m_{i} \ddot{q}_{i}(t)+c_{i} \dot{q}_{i}(t)+k_{i} q_{i}(t)=f_{i}(t)\right\}_{i}$ where $m_{i}, c_{i}$ and $k_{i}$ are the modal mass, damping and stiffness of the $i$ th mode. The damping factor $\xi_{i}$ is defined as

$c_{i}=2 \xi_{i} \sqrt{k_{i} m_{i}}$

The projection of the external forces $F(t)$ on the $i$ th mode is $f_{i}(t)$. This projection takes into account the fact that the displacement at the end of the tool is different from that on the magnetic bearing level

$f_{i}(t)=\varphi_{i}(0) F(t)$

The resulting system of equations is the following:

$\left\{m_{i} \ddot{q}_{i}(t)+c_{i} \dot{q}_{i}(t)+k_{i} q_{i}(t)=\varphi_{i}(0) F(t)\right\}_{i}$

In addition to the flexible modes, it is necessary to take into account the static rigid mode of the rotor, because the rotor is free. Indeed there is a static component of the excitation force that will be compensated by the feedback control loop. As a simplification, we will consider that the spindle is mainly moving at the A bearing level and that $\mathrm{B}$ bearing can be considered as a hinge (see Fig. 2).

The mass of the rotor is $m_{r}$ and length $L$. As a rough approximation we will consider that the rotor is a uniform bar. The $\theta$ angle is considered very small $(L \gg x)$ and the Newton equation is

$\frac{m_{r}}{3} \ddot{q}_{0} \approx F(t)$

The spindle dynamics will be modelized in the $x z$ plane, mechanically defined by its mass and the two first flexible modes. A residual stiffness was tried to be added to compensate modal truncation, but this term was removed due to numerical problems during simulation. The modal parameters were identified by hammer impact at the tip

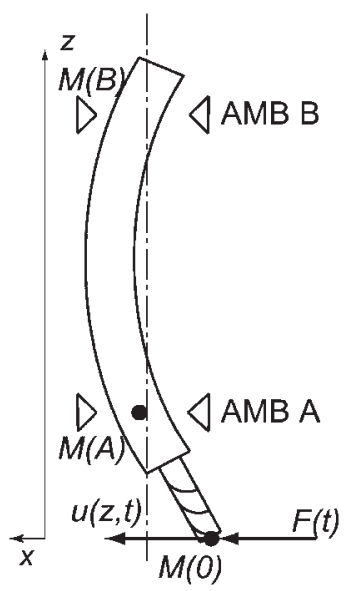

Fig. 1. Mechanical modeling of the spindle.

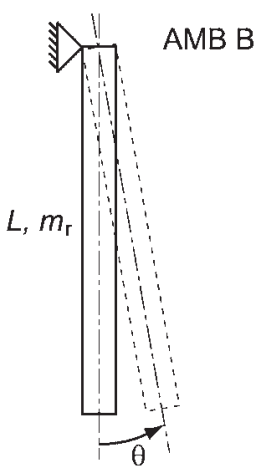

Fig. 2. Rigid mode. 
tool, and the mass rotor was measured. Fig. 3 shows the frequency response function at the tip tool, measured and simulated. The correlation is correct for the detection of resonance peaks. However, at very low frequency, the measure does not restore completely the behavior of the spindle, because it should bring up a flexibility, which tends to infinity. This point is particularly well illustrated by the simulation. Frequencies above $2000 \mathrm{~Hz}$ are not modeled due to modal truncation.

\subsection{Cutting forces}

The relationship between the chip thickness and the tool's vibration may generate self-generated vibrations, which are different from forced or transitional vibrations. This relative self-generated movement between the tool and the workpiece usually leave chatter marks, strongly linked with natural vibrations frequencies of the machining system (see Fig. 4).

With the use of a linear cutting law, the force is proportional to the depth of cut $h(t)$ [10], and defined as follow:

$$
F_{c}(t)=\left[K_{1} h(t)\right] g(t) r(h(t))
$$

$g(t)$ function is an Heaviside function that is equal to 1 when the tooth is cutting, and equal to 0 otherwise. $K_{1}$ is a cutting coefficient defined as follow:

$K_{1}=\frac{1}{2} A_{p} K_{t} \alpha_{x}$

with $K_{t}$ the specific tangential cutting coefficient, $A_{p}$ the axial depth of cut, $\alpha_{x}$ the $x$ directional milling force coefficient. This last coefficient represents the mean value of the variable cutting force of a tooth. It is calculated as follow:

$\alpha_{x}=\frac{1}{2}\left[-\cos (2 \theta)-2 \theta k_{r}-k_{r} \sin (2 \theta)\right]_{\phi_{s t}}^{\phi_{\text {ex }}}$

with $k_{r}$ the reduced radial cutting coefficient, $\phi_{s t}$ and $\phi_{e x}$ are the entry and exit cutting angle of the tool, defined as follow, for

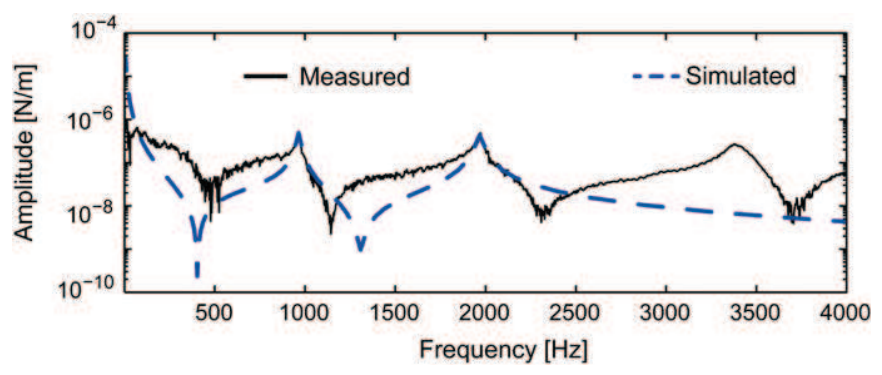

Fig. 3. Transfer function at the tool tip.

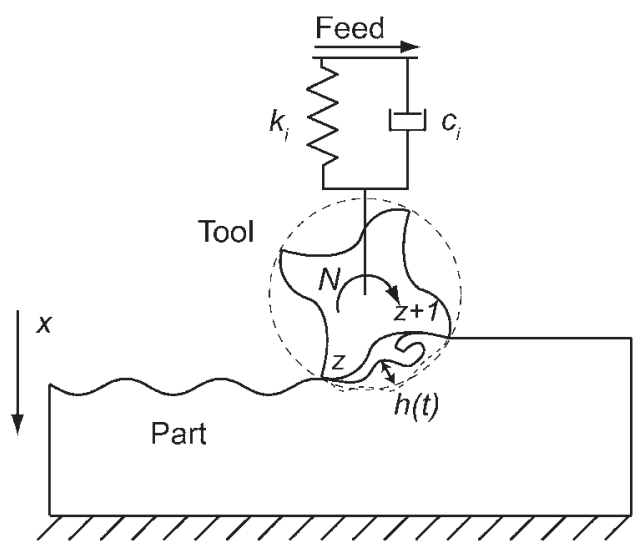

Fig. 4. Mechanical modeling of the milling process. down-milling:

$\left\{\begin{array}{l}\phi_{s t}=\arccos \left(\frac{A_{e}}{R}-1\right) \\ \phi_{e x}=\pi\end{array}\right.$

$A_{e}$ is the radial depth of cut and $R$ is the tool's radius. The instantaneous chip thickness involved in Eq. (8), is defined as follow:

$h(t)=f_{z}+x(t-\tau)-x(t)$

with $f_{z}$ the feed per tooth, $x(t)$ the current position of the tool and $x(t-\tau)$ the position of the previous tooth. The delay between is defined as follow:

$\tau=\frac{60}{N z}$

with $N$ the spindle speed, in rpm, and $z$ the number of teeth of the tool. The $r(h(t))$ Heaviside function takes into account the fact that, because of vibration, the tool tip may sometimes be outside the matter. It is expressed as follow:

- if $h(t)<0$, i.e. chip thickness is zero, then $r(h(t))=0$, so cutting force is zero,

- if $h(t)>0$, i.e. the tool is cutting, then $r(h(t))=1$, so cutting force is defined with Eq. (8).

It can be noticed that this non-linearity is not always sufficient for limiting vibration amplitude. As mentioned in [12,13], the ploughing effect must also be taken into account. Taking into account the ploughing effect is numerically much more complex than the $r(h(t))$ coefficient and our aim here is not to predict accurately the vibration level but to detect instability, so we will neglect the ploughing effect.

\subsection{Active magnetic bearing}

The Active Magnetic Bearing (AMB) generate a force, coming from the feedback intensity current $i$, in order to maintain the rotor axis position $x$. The magnetic bearings are used in differential mode, i.e. the current in the coils is the sum of an average constant current $i_{0}$, called bias current, and the control current $i$ (see Fig. 5). Using bias current $i_{0}>0$ provide the double control force compared to no bias current, because magnetic forces on the steel spindle can only be attractive. It increase the reactivity of the control, but create heating effect, even when $i=0$.

The law between total force and current intensity $i$ is defined in the following equation:

$F_{a m b}(i, x)=k\left[\frac{\left(i_{0}+i\right)^{2}}{\left(x_{0}-x\right)^{2}}-\frac{\left(i_{0}-i\right)^{2}}{\left(x_{0}+x\right)^{2}}\right]$

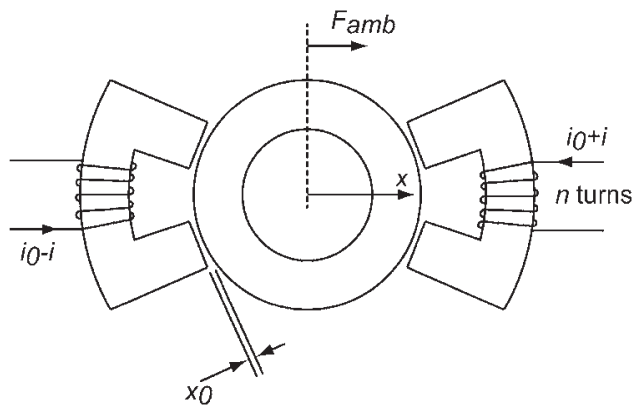

Fig. 5. Rotor supported by magnetic bearings operated in differential mode. 
with $i_{0}$ the bias current, $x_{0}$ the nominal air gap and $k$ the global magnetic permeability calculated as follow:

$k=\frac{1}{4} \mu_{0} A_{g} n^{2}$

where $\mu_{0}$ is the vacuum magnetic permeability, also called magnetic constant, $A_{g}$ is the air gap area and $n$ the number of turns.

\subsection{Control loop}

The knowledge of the control loop is a key point, because it leads to the forces applied to the spindle in reaction to the cutting forces. For this study, the manufacturer of the magnetic bearings (MECOS) has given us all the information we needed to fully understand this control loop and to modify its parameters. It is divided in several parts. First, there is a semi-static control part, which compensates the static forces. Second, there is a dynamic control part, very similar to a proportional derivate regulator with band-cut filters. Third, there is the bias current generation. In practice, there is also a control loop for unbalance compensation, which is not represented here because it is very complicated and because we have experimentally tested that it does not play a significant role in machining dynamics. The modelized structure is represented Fig. 6 .

$G_{x}$ and $G_{i}$ are the position sensor gain factors and the current amplifier gain factor, respectively. They are modelized as simple static gains coefficients. DI is the gain associated to the integrator and A, B, C, D are the matrices defining the Linear Time Invariant (LTI) system used. $\mathrm{IT}_{\max }$ represents the maximum command signal sent from the integration loop. This limitation avoids saturation of the static compensation loop and preserves the LTI role. Then $I_{\max }$ is the maximum intensity current for the coils. In practice, the limits for the integrator, for the LTI and for the bias current are equally balanced each to a third of $I_{\max }$.

\subsection{Resolution of the model}

The time domain simulation must be carefully used to avoid numerical problems because there are many strong non-linearity: delay term, $h(t)$ screen function, maximum limitations IT $_{\max }$ and $I_{\max }$. The numerical integration scheme used is the improved Runge-Kutta $(2,3)$ type [34]. It is an explicit integration scheme. This algorithm is used with a time step adaptation method in order to control stability and approximation error. This algorithm allows dealing with problems strongly nonlinear. The model was implemented in Matlab-Simulink and no numerical problems were detected. The modeling of the system uses:

- mechanical of the spindle (Eq. (6)),

- flexible mode of the rotor (Eq. (7)),

- nonlinearity when the tool leaves the cut under large vibrations (Eq. (8)).

- regenerative effect (Eq. (12)),

- active magnetic bearing (Eq. (14)),

- the servo (Section 2.4).

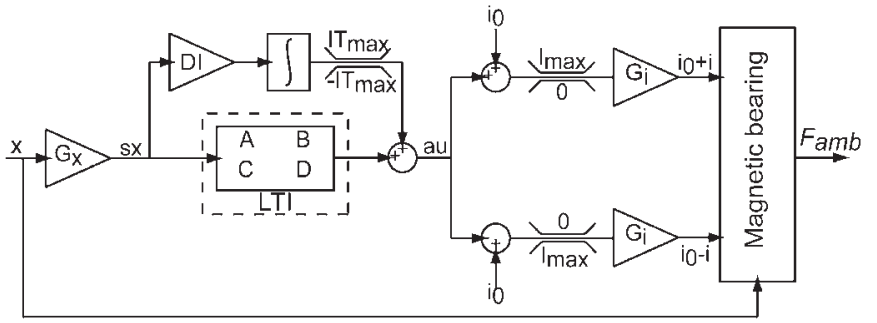

Fig. 6. Structure of the servo.
All this aspects are summarized in the following system of equation:

$\left\{\begin{array}{l}\left\{m_{i} \ddot{q}_{i}(t)+c_{1} \dot{q}_{1}(t)+k_{1} q_{1}(t)+M \ddot{q}_{o}(t)=F_{a m b}-F_{c}\right\}_{i} \\ F_{c}=\frac{1}{2} A_{p} K_{t} \alpha_{x}\left[f_{z}+u(t-\tau)-u(t)\right] g(t) r(h(t)) \\ u(t)=q_{1}(t)+q_{2}(t)+q_{0}(t) \\ x(t)=\varphi_{1} q_{1}(t)+\varphi_{2} q_{2}(t)+q_{0}(t) \\ F_{a m b}(x, i)=k\left[\frac{\left(i_{0}+i\right)^{2}}{\left(x_{0}-x\right)^{2}}-\frac{\left(i_{0}-i\right)^{2}}{\left(x_{0}+x\right)^{2}}\right]\end{array}\right.$.

\section{Stability analysis of Active Magnetic Bearing Spindle machining}

\subsection{Preliminary stability lobes without AMBS}

Here, a classic spindle-tool is modeled without AMBS. To compare different modeling, stability boundaries are predicted by the classical approximation [3] and by the improved semidiscretization [7]. For the computation, we directly use the results presented and justified in the following work [3-5,7,33]. The stability lobes obtained for down milling are shown in Fig. 7. The parameters used for the plot are summarized in Table 1.

The stability boundaries correspond mainly to the Hopf bifurcation instability, which causes quasi-periodic chatter. But, for spindle speeds close to $40000 \mathrm{rpm}$, corresponding to the second bending mode, and because the cutting is highly interrupted,

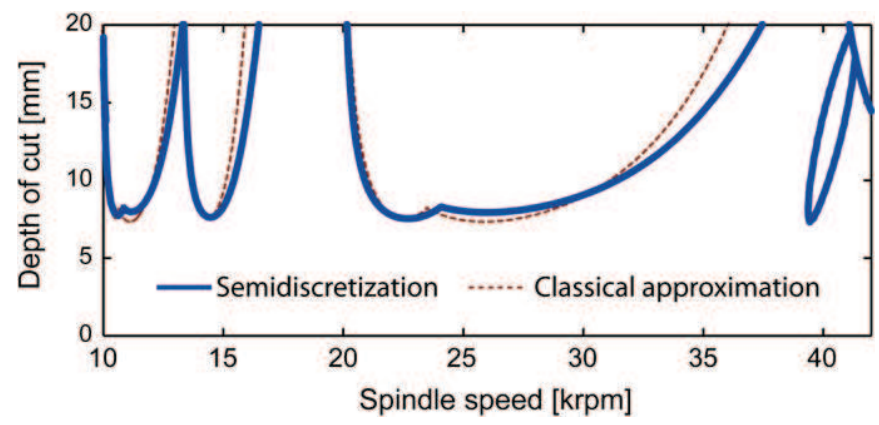

Fig. 7. Classical stability lobes without AMBS.

Table 1

Parameters used for the simulation.

\begin{tabular}{ll}
\hline Dynamical paramaters & Values \\
\hline$m_{1}$ & $2.510 \mathrm{~kg}$ \\
$c_{1}$ & $305.56 \mathrm{Ns} / \mathrm{m}$ \\
$k_{1}$ & $9.3 \times 10^{7} \mathrm{~N} / \mathrm{m}$ \\
$\omega_{1}$ & $970 \mathrm{~Hz}$ \\
$\varphi_{1}$ & 0.01 \\
$m_{2}$ & $0.782 \mathrm{~kg}$ \\
$c_{2}$ & $170.52 \mathrm{Ns} / \mathrm{m}$ \\
$k_{2}$ & $1.2 \times 10^{8} \mathrm{~N} / \mathrm{m}$ \\
$\omega_{2}$ & $1970 \mathrm{~Hz}$ \\
$\varphi_{2}$ & 0.08 \\
$m_{r}$ & $21 \mathrm{~kg}$ \\
Cutting parameters & Values \\
$K_{t}$ & $900 \mathrm{MPa}$ \\
$k_{r}$ & 0.2 \\
$f_{z}$ & $0.1 \mathrm{~mm} / \mathrm{tooth}$ \\
$R$ & $6 \mathrm{~mm}$ \\
$A_{e}$ & $4 \mathrm{~mm}$ \\
$z$ & 3 \\
$\alpha_{x}$ & -1.198 \\
AMB parameters & Values \\
$i_{0}$ & $3 \mathrm{~A}$ \\
$x_{0}$ & $0.4 \mathrm{~mm}$ \\
\hline
\end{tabular}


$A_{e} / D=1 / 3$, there is the appearance of flip bifurcation instability, which cause periodic chatter. This instability, like a small closed curve due to helix angle [33], is only detected by the semidiscretization approach.

These stability plots do not take into account the real behavior of AMBS. Nevertheless, they provide a first approximation of probable stable areas. The contribution of AMBS is clearly emphasized in the next section, with the utilization of the new modeling proposed in this paper.

\subsection{Time domain simulation with AMBS}

\subsubsection{Results of simulation}

The modeling parameters are collected in Table 1 . The helix angle has not been taken into account to limit the computation time, however as shown in Fig. 7, this effect is unimportant and only limited to the flip lobe.

Determining the stability or instability using time domain simulation is always a difficult task. According to [11], the peak to peak criterion was selected. Thus the machining is considered as unstable if the peak to peak amplitude exceeds a given level. Such criterion is very easy to compute. It does not give exactly the stability limit but it gives a vibration amplitude limit, which is very useful practically. The determination of the peak to peak numerical criterion has been defined as follow.

Fig. 8 illustrates for two given cutting conditions, the computed axial depth of cut vs. peak to peak displacement. The $23500 \mathrm{rpm}$ spindle speed is supposed to correspond to the first lobe of the first mode, and $27500 \mathrm{rpm}$ to the second lobe of the second mode. The peak to peak displacement scale is logarithmic. It can be seen that the criterion become much more sensitive after $0.2 \mathrm{~mm}$. So we have chosen to fix the peak to peak criterion to $0.1 \mathrm{~mm}$, which is a reasonable value for machining quality, which is also robust for $A_{p}$ determination and still coherent with classical stability criterion (the difference is less than $0.5 \mathrm{~mm}$ for this two given examples).

The simulation chart obtained with this $0.1 \mathrm{~mm}$ criterion at tool's end is shown in Fig. 9 graph (A). It has been computed by $200 \mathrm{rpm}$ increment, from 10000 to $42000 \mathrm{rpm}$ and $0.5 \mathrm{~mm}$ increment, from 1 to $15 \mathrm{~mm}$. The total computing time is about $6 \mathrm{~h}$ on a standard desktop computer Intel Core Duo $1.73 \mathrm{GHz}-1 \mathrm{Go}$ RAM. It may be noted that the dichotomy method, as used in [15] may significantly reduce the computing time but full simulation guarantees the absence of stability islands. We consider that it is possible to distinguish on graph (A), the contribution of the stability of the AMBS, graph (B); the contribution of the forced vibrations, graph (C). By simply removing the nonlinearity of the tool leaving the cut under large vibrations, i.e. assuming $r(h(t))=1$, this result is presented on graph (B), Fig. 9. Then by simple subtraction, graph (C) shows the forced vibrations contributions. These areas of large forced vibrations are present at $10000,14000,20000$ and $40000 \mathrm{rpm}$. These areas correspond to classical forced vibrations but they affect the dynamical behavior of the spindle more dramatically than the chatter instability.

The evolution of peak to peak amplitude at tool end vs. the axial depth of cut is shown Fig. 10, for 4 spindle speeds.

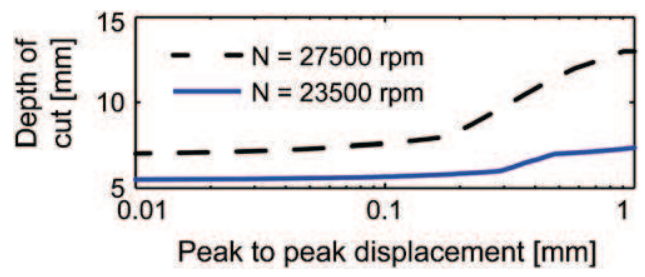

Fig. 8. Evolution of the depth of cut according to the peak to peak displacement.

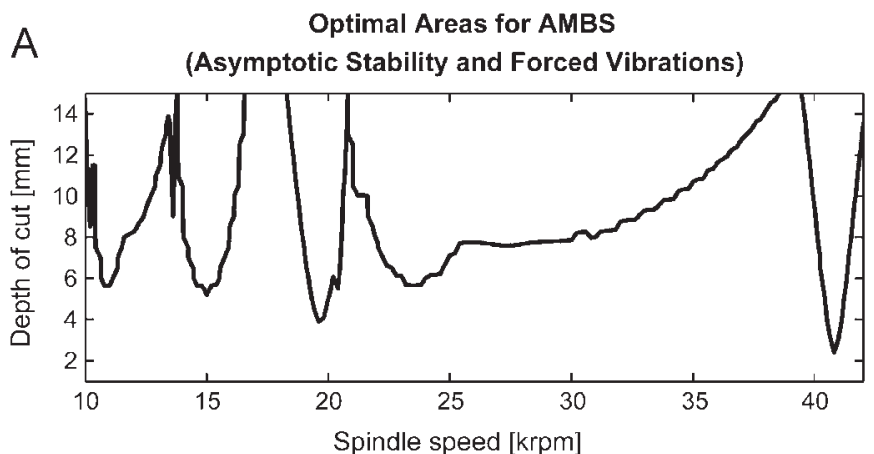

B Contribution of Asymptotic Stability
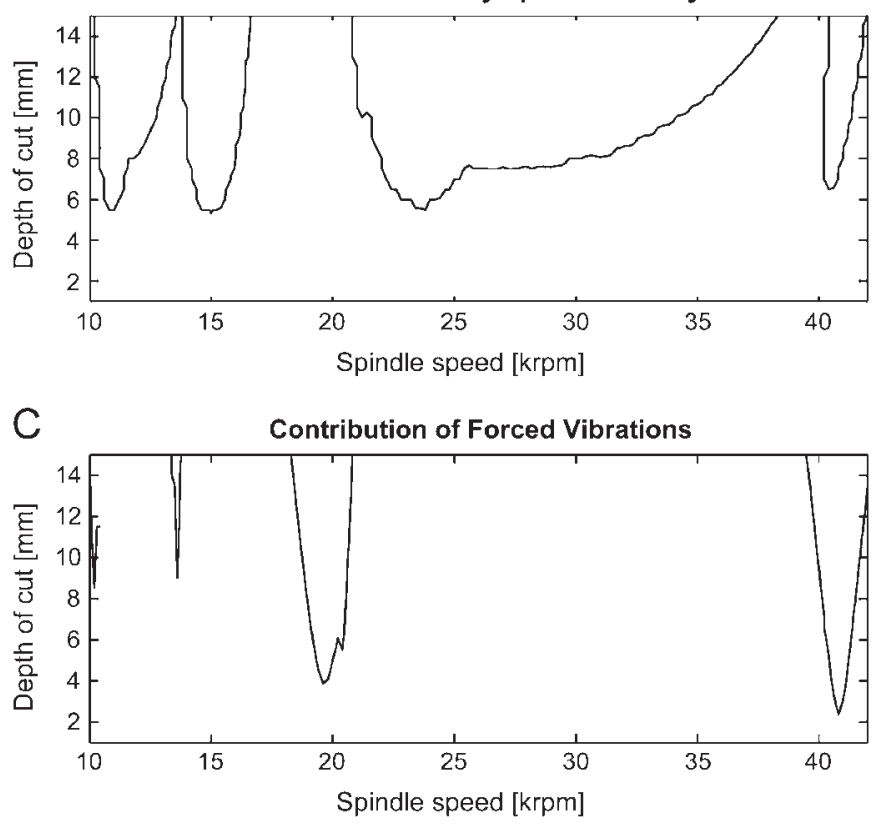

Fig. 9. Optimal areas for the use of a spindle with active magnetic bearing.
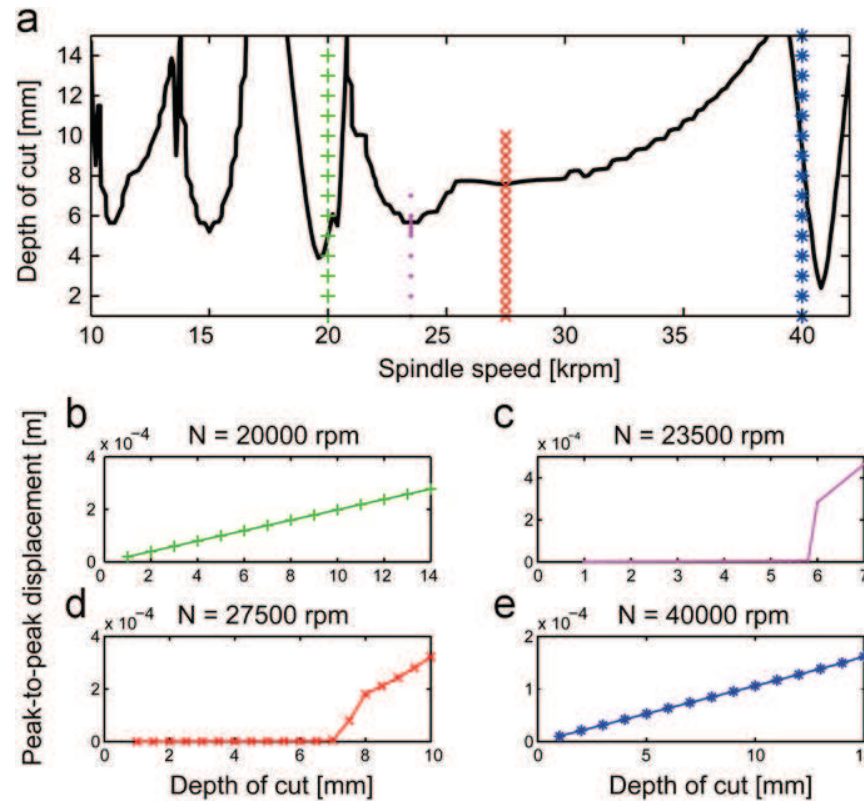

C

$\times 10^{-4} \quad \mathrm{~N}=23500 \mathrm{rpm}$

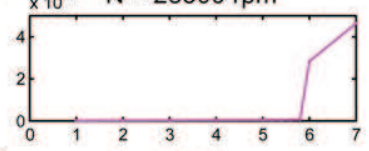

e

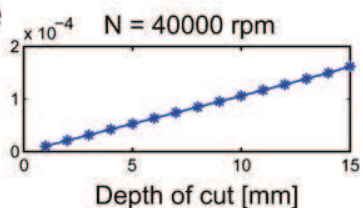

Fig. 10. Displacement analysis of the optimal areas for the use of AMBS 

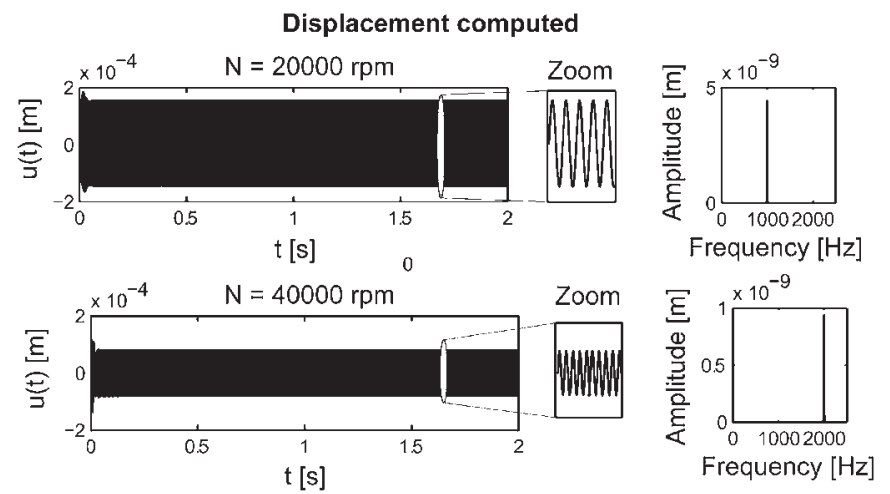

Fig. 11. Frequency analysis of the simulation at $20000 \mathrm{rpm}$ and $40000 \mathrm{rpm}$.

The (c) and (d) graphs show that after a linear part, a sharp increase in the amplitudes is visible. This corresponds to the onset of chatter at the critical depth of cut, characteristic of asymptotic instability. In graphs (b) and (e), the vibration amplitudes can be seen to increase almost linearly with the axial depth of cut. A frequency analysis is presented to determine the nature of these vibrations during machining. Fig. 11 shows the frequency analysis of the displacement for these particular spindle speeds and for an axial depth of cut of $15 \mathrm{~mm}$. In both cases only the tooth passing frequency is present. Classically, these cutting cases are associated with stable machining but with a high level of vibrations. However, in the case of milling with AMBS, these forced vibrations are dangerous and the spindle may automatically be stopped by the safety mode.

In this work, the strict concept of stability, widely used for classical spindle, is extended by including the strong forced vibrations. This new concept of optimal areas for the use of a spindle with AMB is necessary. This result, based on this new modeling can be simply considered as the superposition of the stability and the forced vibrations. However, the modeling developed considers a complete coupling between all the different aspects, leading to a single graph (A), in Fig. 9.

\subsubsection{Sensitivity study}

The model includes many parameters and some of them are difficult to determine precisely:

- First, the cutting forces, which are difficult to model in presence of vibrations. We have already chosen to use, like in many publications, the linear cutting law including a nonlinear effect caused by the possible exit of the tool during the vibrations.

- Second, the modal behavior of the spindle, which is particularly important for magnetic bearings. Indeed, all the spindles are designed to minimize the vibrations forces at the bearings. It means that the modal shapes have their nodes as near as possible from the bearings. It is the same for AMBS. It means that roller bearings are designed to improve the stiffness of the spindle as much as possible. Unfortunately the magnetic bearings are less stiff than classic bearings and behave like self-aligning roller bearings.

In the following we have evaluated the sensitivity of some parameters that seems particularly relevant. Fig. 12 shows the influence of the parameters $\varphi_{1}$ and $\varphi_{2}$ representing the modal shape coefficients of the modes 1 and 2 , at the magnetic bearings locations. The black thick curve is the stability plot from Fig. 10, and will be considered as the reference. We have considered that the $\varphi_{1}$ and $\varphi_{2}$ factors should reasonably stay approximately
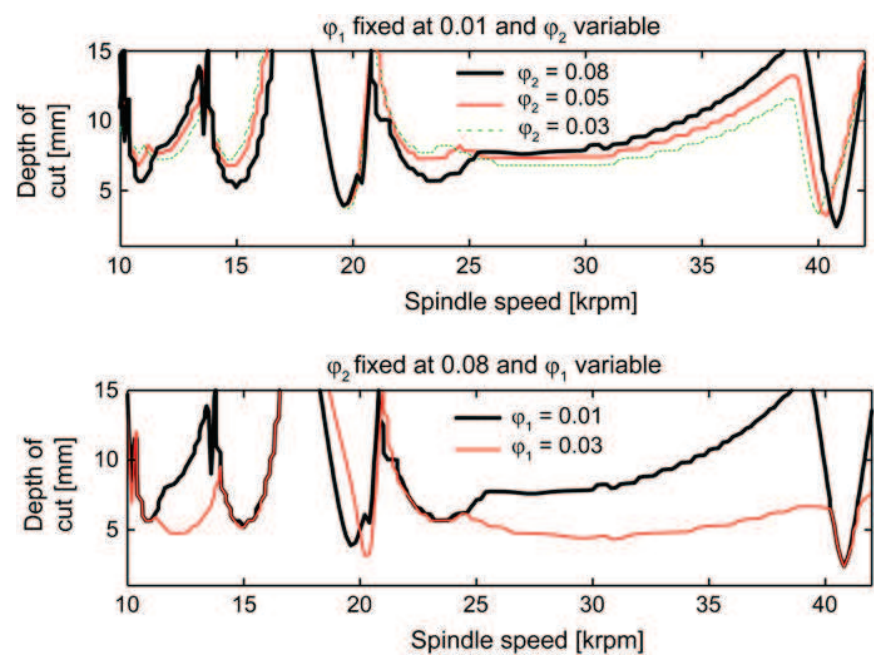

Fig. 12. Results of sensitivity study on the modal contribution at AMBS.

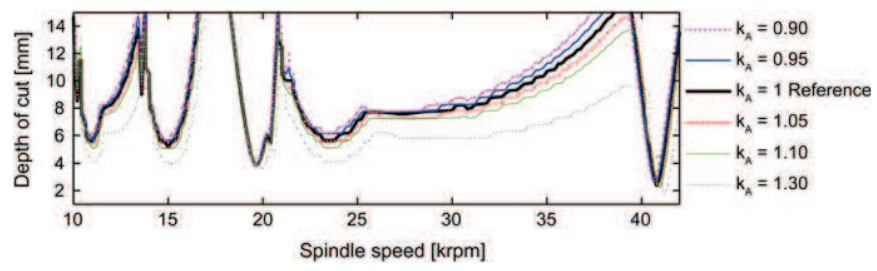

Fig. 13. Results of sensitivity study on servo.

between 0.01 and 0.1 . On the first graph, $\varphi_{1}$ is constant and $\varphi_{2}$ is set at different values. It can be seen that when $\varphi_{2}$ is reduced about 3 times, the stability limit would be modified less than $30 \%$. We will consider that this parameter is not highly sensitive. On the second graph, $\varphi_{2}$ is constant and $\varphi_{1}$ is variable. It can be seen that an increase in 3 times of $\varphi_{1}$ generates a $50 \%$ reduction of the stability limit, but only for the lobes associated to the first mode. It is to notice that we have also made a simulation with $\varphi_{1}=0.05$ that lead to an always instable system. We will consider that this parameter $\varphi_{1}$ is highly sensitive, and especially for the first mode. We had an experimental confirmation of this global sensitivity using a long tool, diameter 16, length $100 \mathrm{~mm}$. Without machining, even without rotation speed, vibrations were clearly audible and we heard similar story from another spindle brand. This behavior is known from the manufacturers who absolutely recommend adjusting the parameters of the command loop when long massive tools have to be used.

As a partial conclusion we would say that the AMBS behavior is very sensitive to the modal behavior.

Fig. 13 shows the influence of the global LTI gain factor $\left(k_{A}\right)$. It can be seen that a $30 \%$ increase in this gain reduces the stability in the same proportion and a $10 \%$ decrease in this gain proportionally increase the stability. A decrease in $k_{A}$ below 0.75 generates system instability. In order to keep a safety margin of $30 \%$, we will consider that $k_{A}=1$ is a good compromise.

\section{Experimental part}

Cutting tests were carried out on a Mikron UCP 600 Vario, 5 axis high-speed milling center with a spindle with Active Magnetic Bearing Ibag HF400M. The tool is a monolithic carbide end mill, three teeth, $12 \mathrm{~mm}$ diameter, helix angle $30^{\circ}$, mounted on a HSK50E. Cutting tests were conducted on a solid block $\left(80 \times 80 \mathrm{~mm}^{2}\right)$ of aluminum $2017 \mathrm{~A}$. The experimental set-up is 


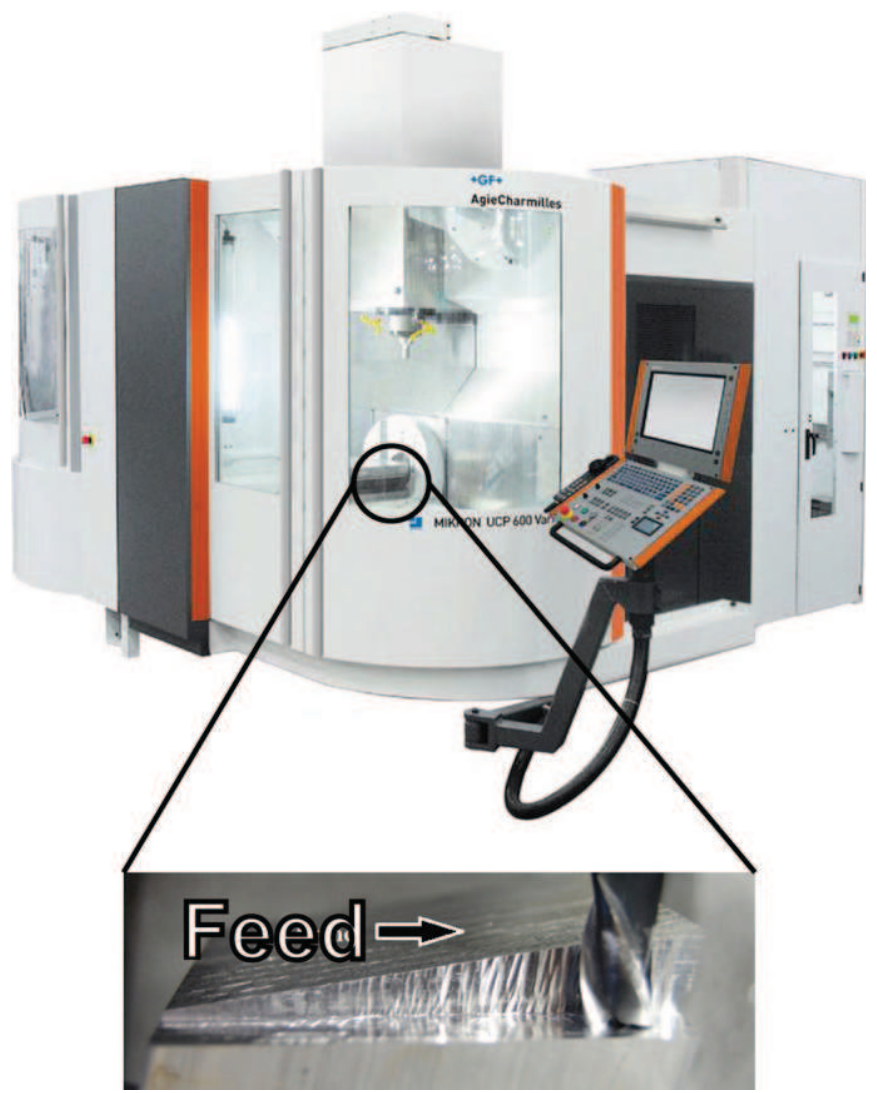

Fig. 14. Experimental set-up.

presented in Fig. 14. After each milling test, the surface was smoothed by a finish pass in order to have for each test the same good initial surface roughness. The part was down-milled with a feed per tooth of $0.1 \mathrm{~mm}$, and a radial depth cut of $4 \mathrm{~mm}$. The axial depth of cut is increased during the machining test. With this new procedure for AMB spindle the axial depth of cut starts at $5 \mathrm{~mm}$ and exit at $12 \mathrm{~mm}$. This original side milling ramp cut is very effective to explore the stability of machining.

The vibrations of the spindle were measured directly using the control signals of the magnetic bearings. In the case of spindle vibration study, this technique has the advantage of not requiring instrumentation. However, the bandwidth is limited to $2.5 \mathrm{kHz}$, and the obtained signal depends on the sensor position, which is quite near the nodes of the spindle vibration modes.

\subsection{Vibrations analysis}

Two useful information are easily available from the control signals of magnetic bearings: the position of the rotor center and the magnetic bearings drive currents. In practice, we preferentially used the control currents signals, because they naturally amplify the cutting force variations. In contrast, the extracted information is indirectly related to the level of vibration. In the remainder of this section, we present the signal processing methods used, because the identification of stable or unstable behavior of a machine through these signals is not necessarily obvious. In some cases, the transition from stable to unstable state is obvious. As an example, the raw signal, the spectrum and the sampled signal once per tool revolution are shown in Fig. 15 for $N=22500 \mathrm{rpm}$ and in Fig. 16 for $N=20000 \mathrm{rpm}$. Then the $1 / \mathrm{rev}$ samples are used to construct experimental Poincaré sections, typical here of unstable process.
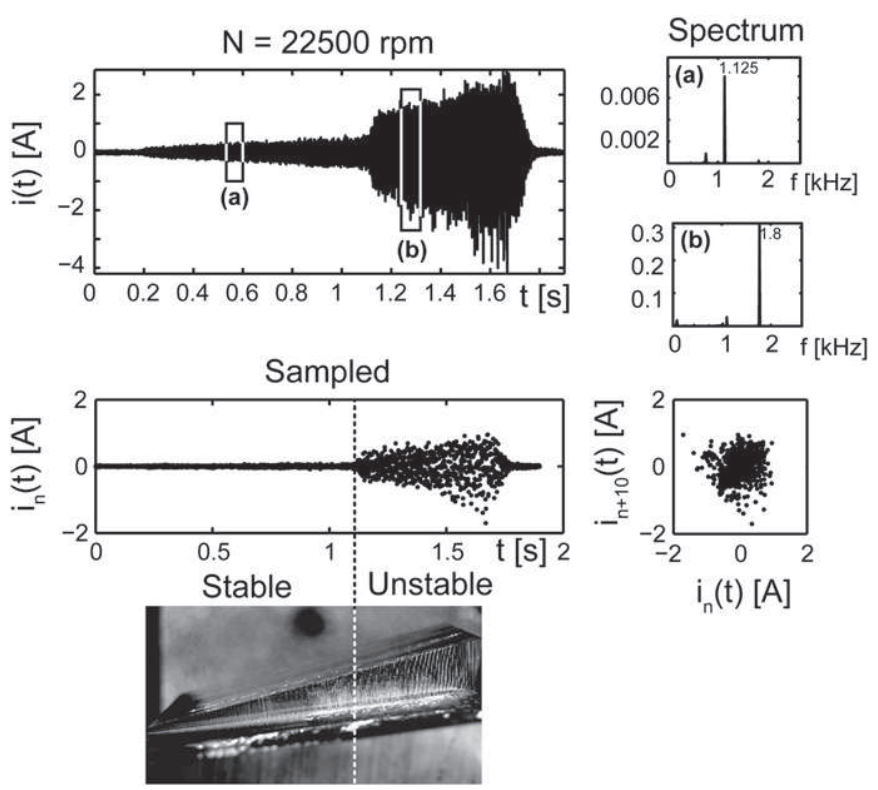

Fig. 15. Continuous time histories, experimental spectrum, $1 /$ rev sampled signals, and Poincaré section for a machining with $N=22500 \mathrm{rpm}$.

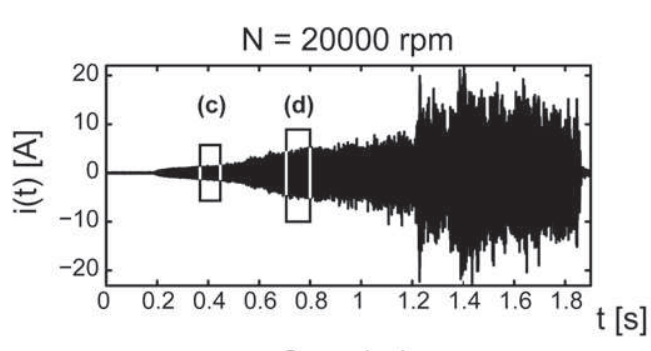

Spectrum

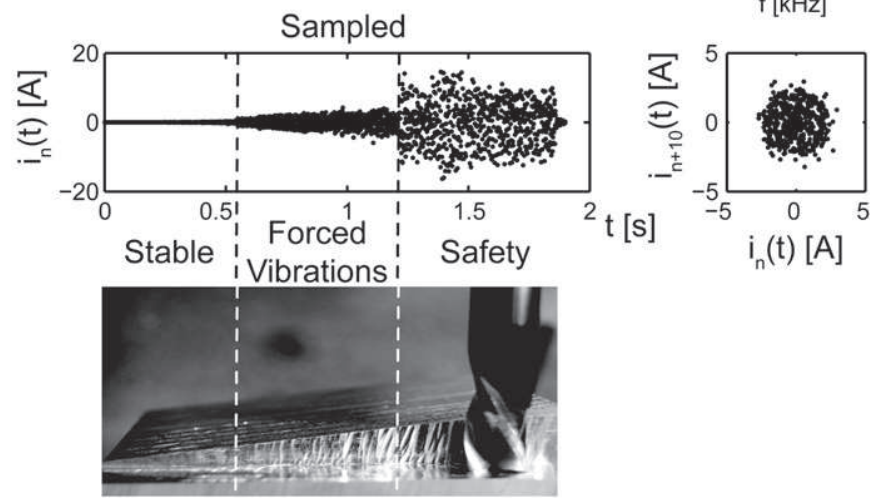

Fig. 16. Continuous time histories, experimental spectrum, $1 /$ rev sampled signals and Poincaré section for a test at $20000 \mathrm{rpm}$.

In Fig. 15, the instability is clearly identifiable. Indeed, in the first phase of machining (a), the amplitude of the measured signals increases linearly, then from $t=1.1 \mathrm{~s}$, a rapid increase is observed, reflecting the shift to unstable machining (b). The experimental spectrum of the data of the area (a) shows only the tooth passing frequency $(1.125 \mathrm{kHz}, 3$ teeth tool, $N=22250 \mathrm{rpm})$. But after $t=1.1 \mathrm{~s}$, area (b) the spectrum is dominated by the chatter frequency $(1.8 \mathrm{kHz})$, different of the tooth passing but close to the second mode $\omega_{2}(1.97 \mathrm{kHz})$. This phenomenon is highlighted by a disk attractor in the Poincaré section.

In contrast, in the following case (see Fig. 16), it is difficult to identify the critical depth of cut only by the observation of the measured signals. However, this machining with $N=20000 \mathrm{rpm}$ 


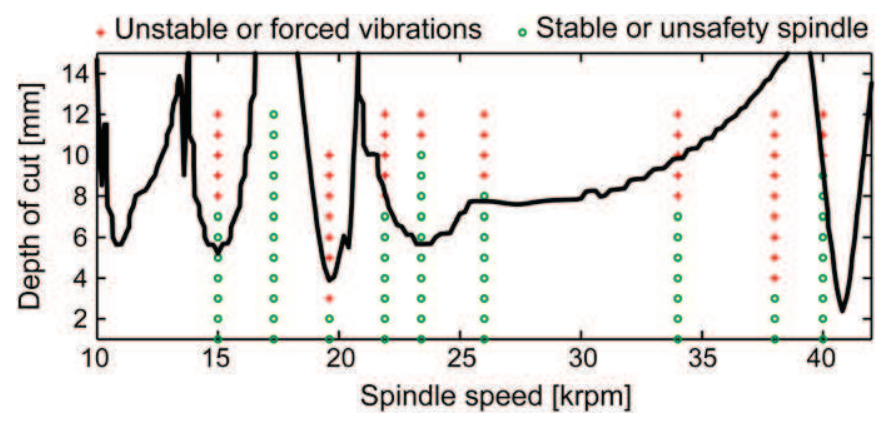

Fig. 17. Comparison between modeling and experiments.

clearly pose problem, since the forced vibrations were so strong that the spindle automatically went into safety mode (i.e. stopped). Fig. 16 shows the measured control current during this test, after filtering low frequencies $(50 \mathrm{~Hz})$, and the experimental spectrum. During the first $0.5 \mathrm{~s}$, area (c), the spectrum shows only the tooth passing frequency ( $1 \mathrm{kHz}, 3$ teeth tool, $N=20000 \mathrm{rpm}$ ) corresponding to stable machining. After $t=0.5 \mathrm{~s}$, large forced vibrations are shown on the spectrum (d). By sampling the signal at the tooth passing frequency, we can clearly observe a loss of regularity of the cut at $t=0.5 \mathrm{~s}$, again, the Poincare section associated with this signal has a disk-type attractor, which implies a strong irregular motion, corresponding in this case to unstable machining.

Indirect measurement of machining vibrations with the control signals of magnetic bearings is a convenient and efficient means to assess the stability of machining, because a lot of sensors are already integrated on the spindle.

\subsection{Discussion simulations-experiments}

The experimental results are plotted on the optimal areas for the use of a spindle with active magnetic bearing in Fig. 17. More than 100 cutting tests have been performed in different zones (stable area, unstable area due to Hopf bifurcation of the first and second bending mode and forced vibration area) to emphasize the behavior highlighted by the simulation. A quite good agreement is observed between numerical simulations and machining tests. Instabilities related to the classical stability lobes theory are found here at 15000, 22000 and $23000 \mathrm{rpm}$. Moreover, high vibration levels predicted by the simulation at $20000 \mathrm{rpm}$ have been encountered during testing. They have even led to automatic emergency stop of the spindle. The test at $40000 \mathrm{rpm}$ does not show so much vibration than the $20000 \mathrm{rpm}$ one.

The test at $37000 \mathrm{rpm}$ shows vibrations much sooner than expected. The discrepancies between the experiment and the modeling are observed for some spindle speed. It is presently not clear what causes these discrepancies. Possible causes could be: the too simple linear cutting law, the simplified chip thickness calculation or the simplified AMB modeling. According to various simulations (see for example [13]), a nonlinear cutting law seems to be always more accurate at low radial depth of cut, but need more coefficient to be determined.

\section{Conclusions}

In this article, the dynamical modeling of Active Magnetic Bearing Spindle (AMBS) is investigated in the case of High-Speed Milling (HSM) process. Based on both simulation and experimental investigations, the following points are made clear:
(1) Classical stability lobes theory, widely used for the chatter optimization of flexible tool with roller bearing spindle, is not adapted for the dynamical modeling of such new milling machine equipped with AMBS.

(2) A quite comprehensive and simple numerical model for machining with AMBS is proposed. This model uses: the $A M B$ and the servo, the flexible mode of the rotor, the regenerative effect and the nonlinearity when the tool leaves the cut under large vibrations. All this elements are naturally linked to the electro-mechanical system and must absolutely be included in the model in order to obtain acceptable results.

(3) A sensitivity analysis showed that the stability of the machining process is very sensitive to the position of the nodes of rotor's flexible modes. Unfortunately these parameters are practically very difficult to determine. A marginal gain on the stability limit of machining is possible, by adjusting the LTI gain.

(4) For a spindle with AMB, it is essential to take into account the strong forced vibrations, because they can induce safety stop. The classic stability chart is heavily modified, because new wide areas in HSM zone are not usable for the machining safety. The new diagram with the optimal areas for the use of a spindle with active magnetic bearing is presented. It is a fundamental advance, highlighted by this work.

(5) An original side milling ramp cut was used for AMBS milling. There are a reasonable correlation between the simulation and the experiment test, which confirms the assumptions for the spindle modeling and the dangerousness of the forced vibrations.

(6) The dynamic model presented here can be used, modified and improved easily: the equations are clarified in the article, most of the parameters can be given by the machining properties and the resolution is carried out by a classical numerical scheme using Matlab-Simulink.

\section{Acknowledgments}

The authors acknowledge the French Ministry of Science for its financial support. The authors would also like to thank Gilles DESSEIN (ENIT-LGP), René LARSONNEUR (IBAG France) and Philippe LEDOUX (GF AgieCharmilles) for their valuable suggestions.

\section{References}

[1] S. Tobias, W. Fishwick, Theory of regenerative machine tool chatter, Engineer 205 (1958) 199-203, 238-239.

[2] H.E. Merrit, Theory of self-exited machine-tool chatter, contribution to machine-tool chatter, research-1, Transactions of the ASME, Journal of Engineering for Industry 87 (1965) 447-454.

[3] Y. Altintas, E. Budak, Analytical prediction of stability lobes in milling, Annals of the CIRP 44 (1995) 357-362.

[4] E. Budak, Y. Altintas, Analytical prediction of chatter stability in milling part I general formulation, Transactions of the ASME, Journal of Dynamic Systems, Measurement, and Control 120 (1998) 22-30.

[5] E. Budak, Y. Altintas, Analytical prediction of chatter stability in milling part II: application of the general formulation to common milling systems, Transactions of the ASME, Journal of Dynamic Systems, Measurement, and Control 120 (1998) 31-36.

[6] P.V. Bayly, J.E. Halley, B.P. Mann, M.A. Davies, Stability of interrupted cutting by temporal finite element analysis, Transactions of the ASME, Journal of Manufacturing Science and Engineering 125 (2003) 220-225.

[7] T. Insperger, G. Stépán, Uptaded semi-discretization method for periodic delay-differential equations with discrete delay, International Journal for Numerical Methods in Engineering 61 (2004) 117-141.

[8] S.D. Merdol, Y. Altintas, Multi frequency solution of chatter stability for low immersion milling, Transactions of the ASME, Journal of Manufacturing Science and Engineering 126 (2004) 459-466.

[9] T. Insperger, G. Stépán, J. Turi, On the higher-order semi-discretizations for periodic delayed systems, Journal of Sound and Vibration 313 (2008) 334-341. 
[10] B.P. Mann, T. Insperger, G. Stépán, P.V. Bayly, Stability of up-milling and down-milling, part 2: experimental verification, International Journal of Machine Tools and Manufacture 43 (2003) 35-40.

[11] S. Smith, J. Tlusty, Efficient simulation programs for chatter in milling, Annals of the CIRP 42 (1993) 463-466.

[12] S. Seguy, G. Dessein, L. Arnaud, Surface roughness variation of thin wall milling, related to modal interactions, International Journal of Machine Tools and Manufacture 48 (2008) 261-274.

[13] L. Arnaud, O. Gonzalo, S. Seguy, H. Jauregi, G. Peigné, Simulation of low rigidity part machining applied to thin walled structures, International Journal of Advanced Manufacturing Technology 54 (2011) 479-488.

[14] M.L. Campomanes, Y. Altintas, An improved time domain simulation for dynamic milling at small radial immersions, Transactions of the ASME, Journal of Manufacturing Science and Engineering 125 (2003) 416-422.

[15] G. Peigné, H. Paris, D. Brissaud, A. Gouskov, Impact of the cutting dynamics of small radial immersion milling operations on machined surface roughness, International Journal of Machine Tools and Manufacture 44 (2004) 1133-1142.

[16] V. Thevenot, L. Arnaud, G. Dessein, G. Cazenave-Larroche, Influence of material removal on dynamic behavior of thin walled structure in periphera milling, Machining Science and Technology 10 (2006) 275-287.

[17] F.J. Campa, L.N. Lopez de Lacalle, G. Urbicain, A. Lamikiz, S. Seguy, L. Arnaud, Critical thickness and dynamic stiffness for chatter avoidance in thin floors milling, Advanced Materials Research 188 (2011) 116-121.

[18] G.S. Duncan, M.F. Tummond, T.L. Schmitz, An investigation of the dynamic absorber effect in high-speed machining, International Journal of Machine Tools and Manufacture 45 (2005) 497-507.

[19] E. Budak, An analytical design method for milling cutters with nonconstant pitch to increase stability, part I: theory, Transactions of the ASME, Journal o Manufacturing Science and Engineering 125 (2003) 29-34.

[20] M.D. Sims, B.P. Mann, S. Huyanan, Analytical prediction of chatter stability for variable pitch and variable helix milling tools, Journal of Sound and Vibration 317 (2008) 664-686

[21] M. Zatarain, I. Bediaga, J. Muñoa, R. Lizarralde, Stability of milling processes with continuous spindle speed variation: analysis in the frequency and time domains, and experimental correlation, Annals of the CIRP 57 (2008) 379-384.
[22] S. Seguy, G. Dessein, L. Arnaud, T. Insperger, Control of chatter by spindle speed variation in high-speed milling, Advanced Materials Research 112 (2010) 179-186.

[23] S. Seguy, T. Insperger, L. Arnaud, G. Dessein, G. Peigné, Suppression of period doubling chatter in high-speed milling by spindle speed variation, Machining Science and Technology 15 (2011) 153-171.

[24] H. Bleuler, M. Cole, P. Keogh, R. Larsonneur, E. Malsen, R. Nordmann, Y. Okada, G. Schweitzer, A. Traxler, Magnetic Bearings, Theory, Design, and Application to Rotating Machinery, Springer, 2009.

[25] A. Chiba, T. Fukao, O. Ichikawa, M. Oshima, M. Takemoto, D. Dorrell, Magnetic Bearings and Bearingless Drives, Elsevier, 2005.

[26] N.C. Tsai, R.M. Lee, Regulation of spindle position by magnetic actuator array, International Journal of Advanced Manufacturing Technology 53 (2011) 93-104.

[27] C. Knospe, Active magnetic bearings for machining applications, Control Engineering Practice 15 (2007) 307-313.

[28] M.H. Kimman, H.H. Langen, R.H. Munning Schmidt, A miniature milling spindle with active magnetic bearings, Mechatronics 20 (2010) 224-235.

[29] S. Auchet, P. Chevrier, M. Lacour, P. Lipinski, A new method of cutting force measurement based on command voltages of active electro-magnetic bearings, International Journal of Machine Tools and Manufacture 44 (2004) 1441-1449.

[30] M. Chen, C.R. Knospe, A new approach to the estimation of cutting dynamics using active magnetic bearings, Transactions of the ASME, Journal of Manufacturing Science and Engineering 127 (2005) 773-780.

[31] M. Chen, C.R. Knospe, Control approaches to the suppression of machining chatter using active magnetic bearings, IEEE Transactions on Control Systems Technology 15 (2007) 220-232.

[32] J.H. Kyung, C.W. Lee, Controller design for a magnetically suspended milling spindle based on chatter stability analysis, JSME International Journal Series C-Mechanical Systems Machine Elements and Manufacturing 46 (2003) 416-422.

[33] M. Zatarain, J. Muñoa, G. Peigné, T. Insperger, Analysis of the influence of mill helix angle on chatter stability, Annals of the CIRP 55 (2006) 365-368.

[34] P. Bogacki, L.F. Shampine, A 3(2) pair of Runge-Kutta formulas, Applied Mathematics Letters 2 (1989) 321-325. 